\begin{tabular}{l|l}
\hline SISTEMA \\
ELETRONICO \\
DE REVISTAS \\
SER I UfPR
\end{tabular}

\title{
Fitoterapia na Amazônia: a experiência do estado do Amapá-Brasil ${ }^{1}$
}

\section{Phytotherapy in the Amazon: The Experience of the State of Amapá-Brazil}

\author{
Antonio Sergio Monteiro FILOCREÃO ${ }^{1}$, Alexandre Gomes GALINDO ${ }^{*}$, Terezinha de Jesus Soares dos \\ SANTOS $^{2}$ \\ ${ }^{1}$ Universidade Federal do Amapá (UNIFAP), Macapá, AP, Brasil. \\ ${ }^{2}$ Instituto de Pesquisas Científicas e Tecnológicas do Estado do Amapá (IEPA), Macapá, AP, Brasil. \\ ${ }^{*}$ E-mail de contato: alexandregalindo@bol.com.br
}

Artigo recebido em 25 de outubro de 2015, versão final aceita em 10 de janeiro de 2017.

RESUMO: Este trabalho discute as perspectivas da utilização de plantas medicinais e fitoterápicos na Amazônia, a partir da experiência desenvolvida no Estado do Amapá, localizado na fronteira setentrional da Amazônia brasileira. A pesquisa utilizou os procedimentos metodológicos empregados pela REDESIST da Universidade Federal do Rio de Janeiro para o estudo de Arranjos Produtivos Locais, fazendo as adequações necessárias ao atendimento do Project RISSI e incorporando a inclusão social nos estudos da inovação. A coleta de dados junto a pesquisadores, especialistas, empresários, coletores, curandeiros, garrafeiros mostrou que, apesar da existência de um grande potencial para a produção e uso de fitoterápicos e plantas medicinais na Amazônia pela rica biodiversidade e tradição de uso, a fitoterapia como negócio tem dificuldades de avançar pela restritiva legislação vigente, porém, apresenta uma grande perspectiva de inclusão social na sua forma in natura nas farmácias vivas da rede pública e na medicina popular, amortecendo as deficiências da rede pública de saúde.

Palavras-chave: arranjos produtivos locais; Amazônia; fitoterapia; plantas medicinais.

ABSTRACT: This paper discusses the prospects for the use of medicinal plants in the Amazon, from the experience developed in the State of Amapá, located on the northern border of the Brazilian Amazon. The study used the methodological procedures employed by RedeSist of the Federal University of Rio de Janeiro for the study of Local Productive Arrangements, making the necessary adjustments to meet the Project RISSI, and incorporating social inclusion in studies of innovation. The collection of data from researchers, experts, entrepreneurs, collectors, healers, potion makers showed that, despite the existence of a large potential for the production and

\footnotetext{
1 Artigo baseado na tradução do Capítulo do Livro: Filocreão, A. S. M.; Galindo, A. G. G.; Santos, T. J. S. Phytotherapy in the Amazon: the experience of Amapá-Brazil. In: Cassiolato, J. E.; Soares, M. C. C. (Org.). Health Innovation Systems: Equity and Development. Rio de Janeiro: E-papers, 2015. p. 321-354.
} 
use of phytotherapic medicines and medicinal plants in the Amazon due to the rich biodiversity and tradition of use, the Phytotherapy as business has difficulties advancing because of restrictive legislation. However, it presents a great prospect in social inclusion in its "fresh" form in herbal pharmacies at public health services and in folk medicine, dampening the deficiencies of the public health care network.

Keywords: local productive arrangements; Amazonia; phytotherapy; medicinal plants.

\section{Introdução}

A utilização da riqueza dos recursos da flora e da fauna, existentes nos diversos ecossistemas amapaenses, para atender às necessidades básicas de saúde das populações locais (indígenas, caboclas, ribeirinhas, afrodescendentes e quilombolas) sempre esteve, e continua presente, no cotidiano amapaense, principalmente das populações mais pobres, que habitam no meio rural. No passado, frequentemente, a utilização desses recursos se dava de forma isolada, mas hoje já se encontra geralmente associada aos novos medicamentos vendidos nas farmácias (Oliveira, 2001).

Muitos dos produtos utilizados, como cascas, folhas, raízes, caules são de origem extrativista, comercializados in natura geralmente nas feiras de agricultores. Outros produtos com algum tipo de processamento são ofertados em farmácias de manipulação, cuja matéria-prima também provém predominantemente da atividade extrativista, embora já exista algum tipo de produção cultivada em "farmácias vivas" (Oliveira, 2001).

A utilização das plantas medicinais no tratamento de doenças por parte das populações locais passa a ser objeto de interesse para estudos no ano de 1965, quando é criado, pelo Governo do Território Federal do Amapá, o Escritório Comercial e Industrial do Amapá, que foi dirigido pelo cientista Waldemiro Gomes. O referido escritório iniciou seus trabalhos com uma pequena coleção de fibras, sementes e plantas medicinais, promovendo tam- bém atendimento ao público com doação de mudas e tratamento com produtos fitoterápicos (Almeida, 2001).

Em 1981, com a morte de Waldemiro Gomes, as atividades ligadas à fitoterapia pelo governo territorial são incorporadas à Seção de Plantas Medicinais da Divisão de Botânica do Museu de História Natural Ângelo Moreira da Costa Lima, criado em 1974.

Em 1988, o acervo deixado por Waldemiro Gomes é desmembrado do Museu Costa Lima para fazer parte do acervo do Museu de Plantas Medicinais Waldemiro Gomes, criado naquele mesmo ano e vinculado à Secretaria de Planejamento e Coordenação.

Em 1991, o governo do Estado do Amapá cria o Instituto de Estudos e Pesquisa do Amapá (IEPA), incorporando os Museus Costa Lima e Waldemiro Gomes, criando-se ainda o Centro de Pesquisas em Plantas Medicinais, com o propósito de desenvolver pesquisas em fitoterápicos no governo estadual.

De 1991 até 1994, deu-se continuidade ao trabalho de fitoterapia no IEPA. Entretanto, as ações do instituto estiveram centradas principalmente na esfera do atendimento ambulatorial, não se encontrando trabalhos da época que sistematizassem as atividades do órgão com plantas medicinais e que aplicassem metodologias de pesquisa na área, quer na manipulação de medicamentos, quer no acompanhamento de casos tratados com a fitoterapia (Oliveira \& Nishi, 2001).

Este trabalho discute as perspectivas da utilização de plantas medicinais e fitoterápicos na 
Amazônia, a partir da experiência desenvolvida no Estado do Amapá, localizado na fronteira setentrional da Amazônia brasileira. A pesquisa utilizou os procedimentos metodológicos empregados pela Rede de Pesquisa em Sistemas e Arranjos Produtivos e Inovativos Locais - REDESIST - da Universidade Federal do Rio de Janeiro para o estudo e caracterização de Arranjos Produtivos Locais, fazendo as adequações necessárias ao atendimento do Research on Innovation Systems and Social Inclusion in Emerging Economies and Beyond (Project RISSI), incorporando a inclusão social nos estudos da inovação.

Após esta parte introdutória, o presente trabalho realiza uma breve discussão sobre alguns aspectos contextuais referentes ao arranjo produtivo de fitoterápicos do Amapá e suas características socioeconômicas para, em seguida, discorrer sobre sua caracterização e alternativas de desenvolvimento, tecendo, em conclusão, as considerações finais.

\section{Aspectos contextuais do arranjo produtivo e inovativo local de fitoterápicos do Amapá}

O uso de plantas medicinais é resultado do próprio processo coevolutivo do homem e da natureza, cujo emprego, coleta e cultivo representarão as particularidades de cada cultura. Ao chegar à Amazônia, o europeu encontrou, nas práticas indígenas, a utilização de plantas para a cura de doenças, bem como em rituais como banhos, chás e alimentação. Segundo Carreras \& Gonzalez (2011), o testemunho mais antigo do uso de plantas por razões não alimentares data de aproximadamente 60.000 anos. Esse conhecimento era intenso nas civilizações antigas e sua utilização era a base médica do século XIX. Atualmente, pelo menos $25 \%$ dos produtos farmacêuticos modernos originam-se das plantas, e muitos medicamentos são produzidos a partir de substitutos sintéticos de produtos extraídos de plantas (Carreras \& Gonzalez, 2011).

Para Carreras e Gonzalez (2011), existe um número estimado de 70.000 espécies de plantas medicinais utilizadas em todo mundo, com uma elevada demanda por produtos derivados dessas plantas, tanto para o uso doméstico como para o comércio local, regional, nacional e internacional. Vale destacar que a produção de uma grande quantidade desses produtos depende da coleta no meio silvestre.

O uso de plantas medicinais no Brasil precede a chegada do europeu, pois os índios já utilizavam dos seus conhecimentos práticos na solução de problemas, instrumentalizando a rica flora existente; muitas dessas práticas vão ser utilizadas pelos colonizadores europeus (Daniel, 2004).

Na Amazônia, o padre João Daniel (2004), entre 1757-1776, fez um inventário sobre as riquezas do Amazonas, citando várias plantas que eram utilizadas pelos indígenas na cura de doenças. Esse conhecimento sobre as plantas medicinais manteve-se vivo nas tradições repassadas ao longo do tempo, contribuindo para a sobrevivência das populações que habitavam a floresta (Filocreão et al., 2013).

Apesar da utilização secular das plantas medicinais, o crescimento da indústria farmacêutica moderna inibiu o uso mais intensivo do conhecimento nativo dessa terapia pela população urbana (Carreras \& Gonzalez, 2011). Porém, uma série de eventos, como a busca de práticas alternativas para o controle das doenças, devido ao crescente custo dos medicamentos industriais e à busca de uma vida mais saudável, provocará uma discussão das possibilidades de institucionalização dessa prática nas políticas de saúde pública. Os medicamentos fitoterápicos, quando destinados ao uso humano, são regulamentados pela Agência Nacional de Vigilância Sanitária - ANVISA; para uso veterinário, 
são regulamentados pelo Ministério da Agricultura, Pecuária e Abastecimento - MAPA.

\subsection{Medicamentos fitoterápicos manipulados}

A manipulação de medicamentos fitoterápicos para uso humano é feita em farmácias com autorização da Vigilância Sanitária Estadual ou Municipal (VISA), pois os medicamentos manipulados não precisam ser registrados na ANVISA, sendo o controle da sua produção feito no estabelecimento produtor. A ANVISA não fiscaliza diretamente esses estabelecimentos, exceto quando há alguma denúncia ou solicitação. A manipulação pode ser magistral, quando formulada por profissional habilitado a prescrevê-la, ou oficinal, quando constante no Formulário Nacional de 2006. As fórmulas de fitoterápicos são encontradas no Formulário Fitoterápico Brasileiro, elaborado em 2011, e a norma que regulamenta a manipulação de medicamentos é a Resolução de Diretoria Colegiada RDC n ${ }^{\circ}$ 67/2007/ ANVISA, atualizada pela RDC n ${ }^{\circ} 87 / 2008$ /ANVISA, definindo as boas práticas de manipulação de preparações magistrais e oficinais para uso humano em farmácias (Filocreão et al., 2013).

As farmácias devem ter autorização de funcionamento, e a manipulação de medicamentos deve seguir regras rígidas de controle, cuja finalidade é garantir que os medicamentos sejam disponibilizados ao usuário com a segurança necessária. A produção deve ser feita individualmente, conforme demandado por receita de profissional habilitado a prescrever medicamentos. As farmácias devem adquirir, e não produzir, as matérias-primas a serem utilizadas na manipulação de medicamentos, de fornecedores de insumos qualificados. Recentemente, o Ministério da Saúde publicou a Portaria GM/MS no 886/2010, a qual institui a Farmácia Viva no Âmbito do Sistema
Único de Saúde (SUS), sob gestão estadual, municipal ou do Distrito Federal. A partir daí, a ANVISA elaborou proposta de regulamentação técnica para boas práticas de processamento e manipulação de plantas medicinais e fitoterápicos em Farmácias Vivas, que devem ser estabelecimentos com hortos agregados, sob controle dos órgãos ambientais, Ministério da Agricultura, Pecuária e Abastecimento (MAPA) e do Meio Ambiente (MMA).

\subsection{Medicamentos fitoterápicos industrializados}

A norma vigente para registro de medicamentos fitoterápicos é a Resolução da Diretoria Colegiada (RDC) n $n^{\circ}$ 14/2010/ANVISA, que incorpora, em relação à norma anterior (RDC no 48/04), modificações para adequação aos conceitos definidos pela Política Nacional de Plantas Medicinais e Fitoterápicos (PNPMF) e pela Política Nacional de Práticas Integrativas e Complementares (PNPIC) no SUS. Essa resolução incorpora a adoção de alternativas ao controle de qualidade, que apresenta elevado grau de dificuldade para medicamentos fitoterápicos, devido à complexidade de suas composições químicas. Os requisitos de segurança e eficácia não foram essencialmente modificados, além do item de referências técnico-científicas anterior, ampliado de 17 para 35 publicações de referência para comprovação de segurança e eficácia de fitoterápicos (Instrução Normativa $n^{\circ}$ 05/2010/ANVISA), abrindo-se a possibilidade de comprová-los por três outras formas: ensaios pré-clínicos e clínicos de segurança e eficácia; tradicionalidade de uso; e presença na Lista de Medicamentos Fitoterápicos de Registro Simplificado da ANVISA.

A tradicionalidade de uso pode ser feita por meio da apresentação de estudo etnofarmacológico 
ou etno-orientado de utilização, documentações técnico-científicas ou outras publicações, mostrando a eficácia e segurança do produto por um período igual ou superior a 20 anos. A Lista de Medicamentos Fitoterápicos de Registro Simplificado (Instrução Normativa $n^{\circ}$ 05/2008/ANVISA) contempla 36 espécies vegetais, para as quais já foram estabelecidos critérios de segurança e eficácia. A empresa deve seguir todos os parâmetros especificados na lista citada, que são: parte da planta, padronização/marcador, tipo de derivado vegetal, indicações/ações terapêuticas, dose diária, via de administração, concentração da forma farmacêutica, quando descrita, e restrição de uso, não precisando apresentar informações adicionais deste item (Filocreão et al., 2013).

No Brasil, em 2011, havia 382 medicamentos fitoterápicos, dos quais 357 são fitoterápicos simples e 25, em associação (Perfeito, 2012). Esses fitoterápicos são produzidos a partir de 98 diferentes espécies vegetais. As espécies vegetais com mais registro são, em sua maioria, estrangeiras, como Aesculus hippocastanum (castanha-da-índia), com 22 registros, e Ginkgo biloba (ginkgo), com 20 registros. Entre as brasileiras, as mais registradas são o Mikania glomerata (guaco), com 20 registros; Passiflora incarnata (Maracujá), com 16 registros, e Maytenus ilicifolia (espinheira-santa), com 14 registros. Existem 78 empresas produtoras de fitoterápicos no Brasil, na maior parte, concentradas nas Regiões Sul e Sudeste do país (Perfeito, 2012).

\subsection{Instituto de Estudos e Pesquisa do Amapá e a produção de medicamentos fitoterápicos}

De 1995 a 1998, com a implementação do Plano de Desenvolvimento Sustentável do Amapá
(PDSA), a fitoterapia passa a ser uma prioridade no planejamento estratégico do governo, haja vista o Programa Fitoterapia como alternativa de Saúde Pública. Por meio de uma reforma administrativa em 1977, as atividades de fitoterapia e a Curadoria de Farmácias Vivas ficaram vinculadas à Divisão de Fitoterapia, enquanto as atividades de avaliação clínico-laboratorial (com um projeto de acompanhamento de 150 diabéticos utilizando fitoterápicos) vincularam-se à Divisão de Avaliação Terapêutica, ambas funcionando no novo Centro de Pesquisa em Plantas Medicinais e Produtos Naturais. Associados às mudanças na estrutura administrativa, acréscimos de investimentos foram feitos no IEPA e garantiram um avanço substancial nas pesquisas sobre utilização e validação e no aumento da produção e difusão do uso de fitoterápicos no Estado do Amapá (Oliveira, 2001).

A priorização e os investimentos na fitoterapia ocorridos no IEPA trouxeram resultados positivos crescentes até o ano de 2002, quando ocorreram novas mudanças no governo estadual. Na produção de fitoterápicos, em 1996, a farmácia do IEPA produziu 3.237 unidades de fitoterápicos, atingindo em 2001 a quantidade de 66.218 unidades, com uma ligeira queda em 2002, para 62.956, e caindo bruscamente em 2003, para 16.150 unidades. Quanto ao atendimento à população, em 1996, a quantidade de pessoas atendidas pela farmácia do IEPA foi da ordem de 1.119 indivíduos, atingindo o pico em 2001, com um atendimento de 22.979 pessoas, encerrando o ano de 2002 com 21.046 atendidos (Santos, 2003). Esses números mostram uma demanda crescente e expressiva por fitoterápicos para um Estado com uma população próxima de meio milhão de habitantes (IBGE, 2000).

Outra atividade importante do IEPA na difusão da fitoterapia do Amapá foi o projeto Uso de Plantas Medicinais no Atendimento de Saúde Básica das Comunidades Rurais - Farmácia da Terra. O 
público alvo do projeto foi as comunidades rurais do Estado do Amapá. Foram instaladas 30 unidades do projeto em 14 dos 16 municípios do Estado, com cerca de 800 pessoas envolvidas, entre agentes comunitários de saúde, parteiras, dirigentes comunitários, professores e enfermeiros, que receberam treinamentos específicos sobre os aspectos técnicos e operacionais das ações do projeto.

A criação do IEPA e a tentativa de implementação de uma política de utilização do conhecimento constituído pela população amapaense (enquanto herdeira do conhecimento indígena nativo e do negro deslocado, conhecimento esse que foi mantido ao longo do tempo para resolver os problemas de saúde das populações locais que ficaram isoladas pelo rio Amazonas dos avanços ocorridos na ciência médica), mostram-se como elementos impulsionadores de inovação que precisam ser mais bem entendidos e discutidos enquanto potencialidades e ingredientes da política de inclusão social.

\subsection{Características socioeconômicas vinculadas ao arranjo produtivo e inovativo local de fitoterápicos do Amapá}

Os dados do crescimento econômico do Amapá, na primeira década do século XXI, mostram que a economia amapaense acompanha o crescimento ocorrido na economia brasileira. Na Tabela 1, per- cebe-se que, entre os anos de 2000 a 2010, o PIB amapaense apresenta uma evolução positiva, saindo do valor de 2,357 para 8,265bilhões de reais, o que representa uma evolução de $250,69 \%$, acima do crescimento da economia brasileira, que foi de $219,64 \%$, porém, abaixo do crescimento ocorrido na Região Norte, que foi de $289,73 \%$.

Quanto aos indicadores de desenvolvimento do Amapá, utilizando o Índice da FIRJAN de Desenvolvimento Municipal (IFDM) da Federação das Indústrias do Estado do Rio de Janeiro (FIRJAN), que avalia o desempenho dos municípios brasileiros, inspirado no Índice de Desenvolvimento Humano (IDH), verifica-se que os números do Amapá apresentam acentuadas quedas no período entre 2000 a 2010. Os indicadores extraídos do DATASUS, base de dados do Ministério da Saúde, mostram as dificuldades que o Amapá enfrenta para melhorar os serviços de saúde oferecidos aos cidadãos. Quanto ao número dos profissionais médicos, enfermeiros e farmacêuticos, que são essenciais na prestação dos serviços de saúde, a Tabela 2 mostra que, comparando-se os números desses profissionais por habitantes com os dados da Região Norte e do Brasil, o Amapá encontra-se abaixo das médias nacional e regional. Esses indicadores da evolução mostram que, se não houver investimentos significativos em recursos humanos, a situação, que já é considerada preocupante nos municípios, tende a se agravar, tendo em vista que esses profissionais estão

TABELA 1 - Evolução do PIB Bruto e PIB per capita (R\$ 1.000,00).

\begin{tabular}{|c|c|c|c|c|c|c|}
\hline \multirow{2}{*}{ Região } & \multicolumn{2}{|c|}{ PIB } & \multirow{2}{*}{ Evolução (\%) } & \multicolumn{2}{|c|}{ PIB per capita } & \multirow{2}{*}{ Evolução (\%) } \\
\hline & 2000 & 2010 & & 2000 & 2010 & \\
\hline BRASIL & $1.179 .482 .000,00$ & $3.770 .084 .872,00$ & 219,64 & $6.946,34$ & $19.763,93$ & 184,52 \\
\hline AMAPÁ & $2.357 .036,00$ & $8.265 .965,00$ & 250,69 & $4.941,04$ & $12.346,00$ & 149,87 \\
\hline
\end{tabular}

FONTE: IBGE (2013). 
TABELA 2 - Evolução do número de profissionais da saúde no Amapá.

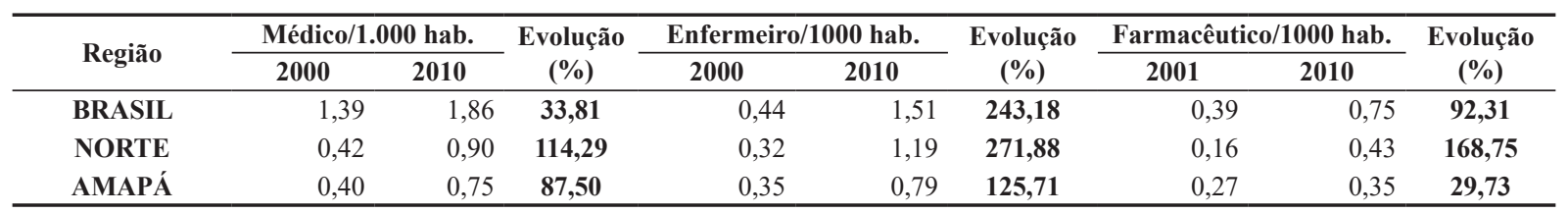

FONTE: DATASUS (2013).

concentrados em Macapá e Santana, onde também se concentra uma infraestrutura insuficiente.

Quanto aos investimentos realizados na saúde, considerando dois importantes indicadores (a proporção dos gastos públicos em saúde, em relação ao PIB, e o número de leitos por habitantes), vamos perceber que (Tabela 3), enquanto os investimentos em saúde no país evoluíram em 21,38\% entre 2002 a 2010, na Região Norte, alcançaram apenas $0,2 \%$ e, no Amapá, a situação piorou, pois houve uma queda de $14,07 \%$ desses investimentos. Quanto ao número de leitos por habitantes no país, ocorreu, entre 1999 a 2009, uma redução de 8,05\%; na Região Norte, uma evolução de $9,8 \%$ e, no Amapá, uma evolução bastante tímida de $0,74 \%$.

A precariedade do sistema de saúde amapaense, com a falta de profissionais e de investimentos capazes de atender ao elevado crescimento demográfico, torna-se ambiente favorável ao uso frequente de plantas medicinais como alternativa de aplicação dos saberes tradicionais para enfrentar problemas de saúde por parte da população

\section{Arranjo produtivo e inovativo local de fitoterápicos do Amapá: stakeholders, capacidade produtiva e de inovação local}

\subsection{Aspectos metodológicos}

Para descrever as características gerais do aglomerado de fitoterápicos do Amapá, foi realizado Survey descritivo-exploratório interseccional por amostragem não probabilística intencional, cuja unidade de análise foi representada pelo conjunto dos principais agentes envolvidos em cada dimensão do estudo, conforme a Tabela 4.

$\mathrm{O}$ método de amostragem foi intencional ou por julgamento, definido por meio dos critérios de acessibilidade e representatividade dos agentes em cada dimensão nos diversos municípios do Estado do Amapá. Os instrumentos de coleta de dados e evidências foram elaborados na perspectiva de contemplar, de forma adaptada, as diretrizes para estudos Arranjos e Sistemas Inovativos Locais e

TABELA 3 - Evolução de investimentos na Saúde no Amapá.

\begin{tabular}{|c|c|c|c|c|c|c|}
\hline \multirow{2}{*}{ Região } & \multicolumn{2}{|c|}{ Gasto Saúde (\% PIB) } & \multirow{2}{*}{ Evolução (\%) } & \multicolumn{2}{|c|}{ Leito/1.000 hab } & \multirow{2}{*}{ Evolução (\%) } \\
\hline & 2002 & 2010 & & 1999 & 2009 & \\
\hline BRASIL & 3,18 & 3,86 & 21,38 & 0,887 & 0,80 & $-8,05$ \\
\hline NORTE & 5,02 & 5,03 & 0,20 & 1,02 & 1,12 & 9,80 \\
\hline AMAPÁ & 6,61 & 5,68 & $-14,07$ & 1,35 & 1,36 & 0,74 \\
\hline
\end{tabular}

FONTE: DATASUS (2013). 
TABELA 4 - Instrumentos e principais variáveis de caracterização.

\begin{tabular}{|c|c|c|}
\hline DIMENSÕES & STAKEHOLDERS & $\begin{array}{lllll}\text { INSTRUMENTOS } & \text { E } & \text { PRINCIPAIS } & \text { VARIÁVEIS } & \text { DE } \\
\text { CARACTERIZAÇÃO } & & & \\
\end{array}$ \\
\hline $\begin{array}{l}\text { CENTRO INDUTOR } \\
\text { DA INOVAÇÃO }\end{array}$ & $\begin{array}{l}\text { 1- Instituto de Pesquisa Científica e } \\
\text { Tecnológica do Amapá-IEPA. } \\
\text { 2- Empresa Brasileira de Pesquisa } \\
\text { Agropecuária-EMBRAPA } \\
\text { 3- Universidade Federal do Amapá- } \\
\text { UNIFAP }\end{array}$ & $\begin{array}{l}\text { INSTRUMENTOS: } \\
\text { Entrevistas semiestruturadas gravadas, complementadas com registro } \\
\text { fotográfico. } \\
\text { PRINCIPAIS VARIÁVEIS: } \\
\text { Linhas de atuação da Divisão de Fitoterapia, o acompanhamento } \\
\text { ambulatorial de grupos tratados com fitoterápicos, a farmácia de produção } \\
\text { e comercialização de fitoterápicos e fitocosméticos e a Curadoria de } \\
\text { Farmácias Vivas, onde são produzidas mudas de plantas medicinais e parte } \\
\text { da matéria-prima utilizada na produção de medicamentos manipulados e } \\
\text { investimentos em pesquisa sobre a fitoterapia. }\end{array}$ \\
\hline
\end{tabular}

\section{INSTRUMENTOS:}

Questionários adaptados da RedeSist, complementados com entrevistas gravadas, registros fotográficos e observações in locus

\section{PRINCIPAIS VARIÁVEIS:}

$\begin{array}{ll}\text { ESTRUTURAS } & \text { 1-Farmácias de Manipulação } \\ \text { INTERMEDIÁRIAS } & \text { 2-Escolas-Famílias } \\ \text { DA INOVAÇÃO } & \text { 3-Farmácias da Terra }\end{array}$

a) Informações sobre a origem das principais matérias-primas, tecnologias utilizadas, relações estabelecidas com fornecedores, tipos de produtos e faturamento.

b) Entender as estratégias adotadas na formação de seus alunos e junto às comunidades sob influências diretas para a difusão do uso de plantas medicinais na resolução de problemas de saúde e como forma de inclusão social.

\begin{tabular}{ll}
\hline & \\
ESTRUTURAS & 1-coletores \\
BÁSICAS & 2-garrafeiros \\
& 3-Benzedeiras/Erveiras/Parteiras
\end{tabular}

\section{INSTRUMENTOS:}

Questionários adaptados da RedeSist.

PRINCIPAIS VARIÁVEIS:

3-Benzedeiras/Erveiras/Parteiras

Informações sobre os locais de coleta, a tecnologia utilizada, informações de faturamento, produtos comercializados. INSTRUMENTOS:

$\begin{array}{ll}\text { ESTRUTURAS DE } & \text { 1- Consumidores Finais das } \\ \text { CONSUMO } & \begin{array}{l}\text { Farmácias de Manipulação } \\ \text { 2- Consumidores Finais das Feiras } \\ \text { de Produtores e Atravessadores }\end{array}\end{array}$

Questionários.

PRINCIPAIS VARIÁVEIS:

Frequência de uso dos fitoterápicos, os motivos da preferência dos principais produtos consumidos, as avaliações percebidas dos seus resultados terapêuticos, além de outras informações que possam indicar aspectos da inclusão social.

inclusão social indicadas por Matos et al., (2012), com o propósito de obter informações sobre: a) as características dos atores, incluindo também o conhecimento sobre plantas medicinais e tratamento fitoterápico; b) os aspectos relacionados com a operação, inovação, cooperação e aprendizagem das organizações envolvidas e c) as características da estrutura, coordenação e ambiente local.

Foi selecionado um montante de 282 agentes relacionados com as dimensões vinculadas ao aglomerado de fitoterápicos do Amapá, que serviram como sujeitos do estudo. A distribuição territorial dos agentes pesquisados encontra-se representada nas Figuras 1 a 4.

Para a caracterização do Arranjo Produtivo Local de fitoterápicos do Estado do Amapá, levaram-se em conta as relações de todos os agentes que possuem potencial de interação direta ou indireta nas principais atividades produtivas do setor, sendo apresentada uma esquematização representativa das respectivas relações no arranjo, conforme propõe Matos et al., (2012). 


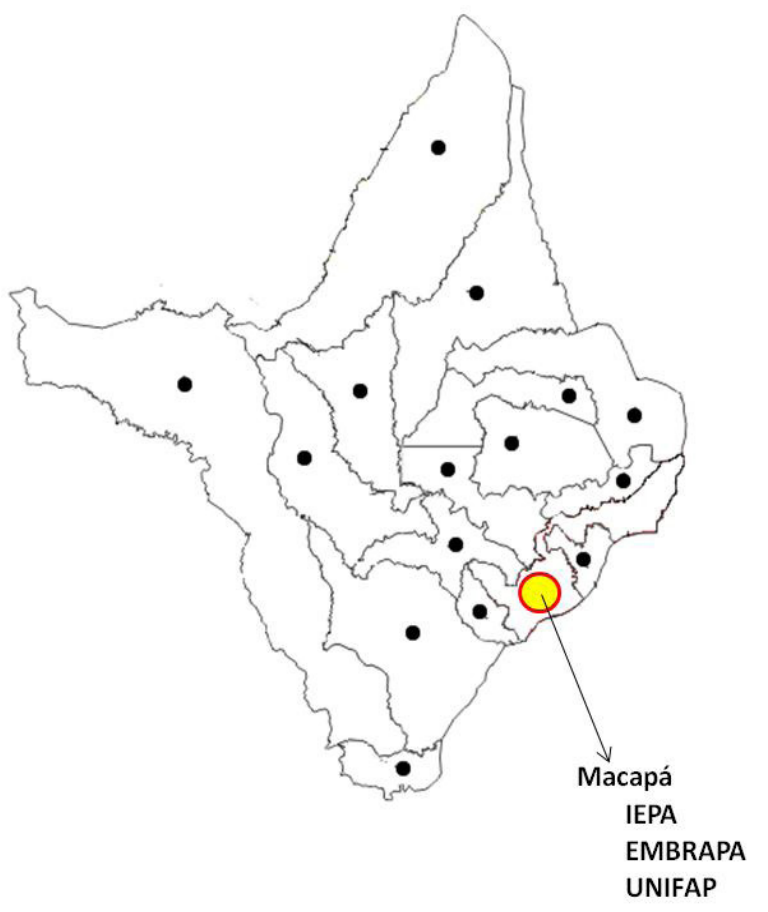

FIGURA 1 - Localização dos agentes vinculados ao Centro Indutor da Inovação do Arranjo Produtivo de Fitoterápicos do Amapá. FONTE: Pesquisa de Campo (2012-2013).

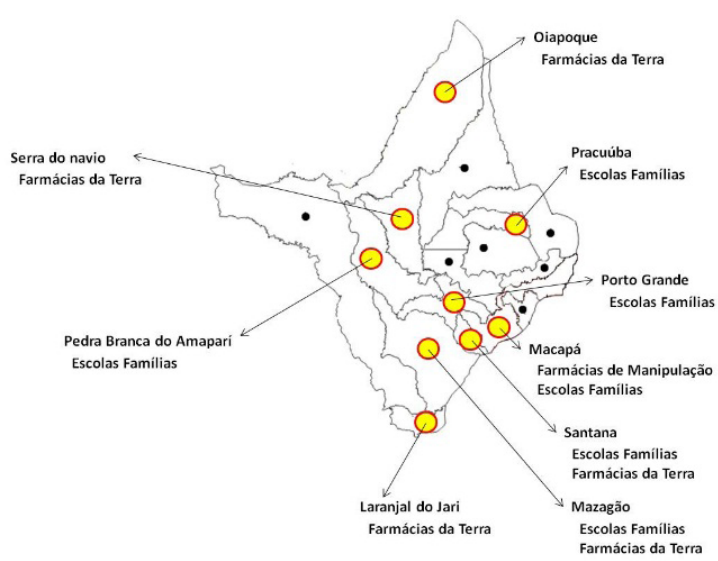

FIGURA 2 - Localização dos agentes vinculados à Estrutura Intermediária da Inovação do Arranjo Produtivo de Fitoterápicos do Amapá.

FONTE: Pesquisa de Campo (2012-2013).

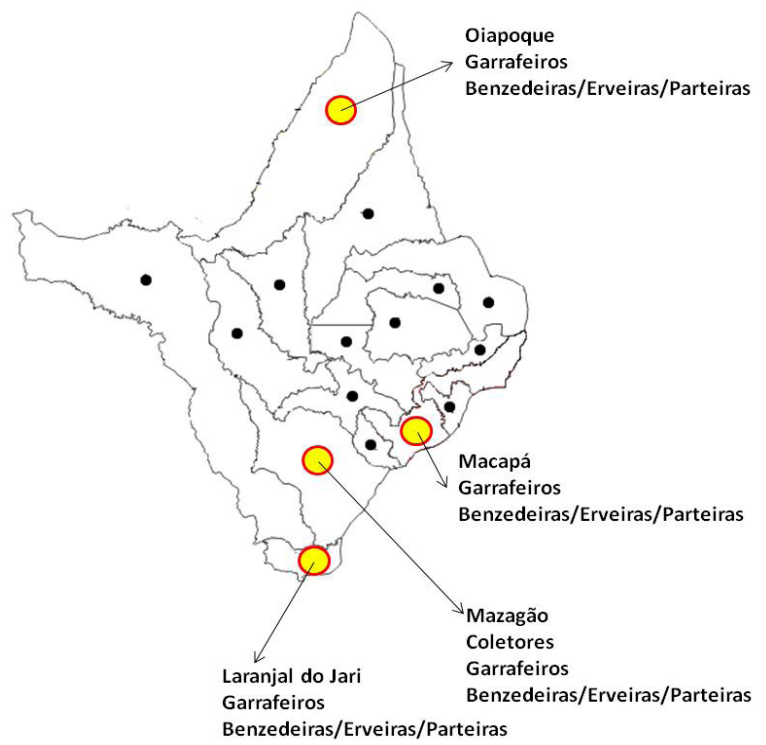

FIGURA 3 - Localização dos agentes vinculados à Estrutura Básica da Inovação do Arranjo Produtivo de Fitoterápicos do Amapá. FONTE: Pesquisa de Campo (2012-2013).

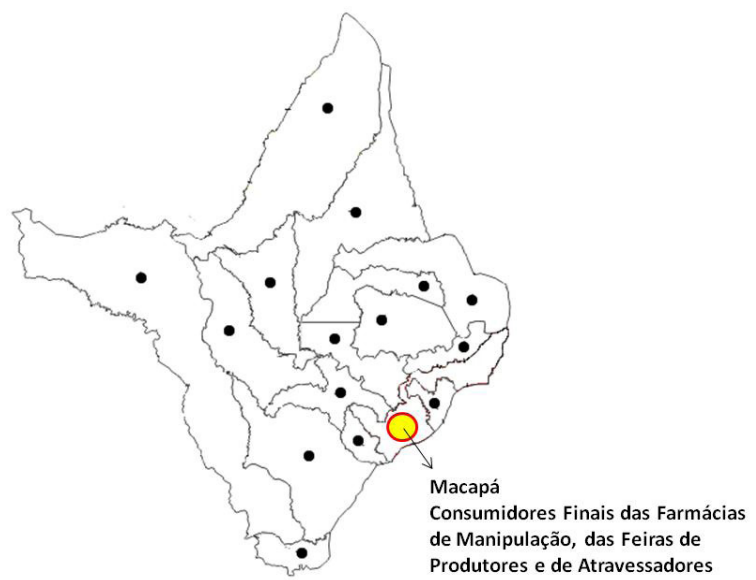

FIGURA 4 - Localização dos agentes vinculados à Estrutura de Consumo do Arranjo Produtivo de Fitoterápicos do Amapá. FONTE: Pesquisa de Campo (2012-2013).

Após a consolidação do relatório preliminar da pesquisa, foi realizado um seminário, agrupando os principais agentes envolvidos no setor para apresentação dos resultados e registro de novas contribui- 
ções para o resultado do estudo. O seminário envolveu atores representativos dos centros indutores de inovação, das estruturas intermediárias de inovação, bem como de outros agentes vinculados ao setor de fitoterápicos. $\mathrm{O}$ evento contou com a participação de 217 participantes representativos dos principais segmentos vinculados ao setor de fitoterápicos no Amapá, como IEPA, UNIFAP, Secretaria de Estado da Ciência e Tecnologia, Centro de Referência em Tratamento Natural do Amapá-CRTN, Conselho Nacional das Populações Extrativistas - CNS, Acadêmicos da área da saúde (Medicina, Farmácia, Enfermagem). As informações obtidas durante o seminário foram sistematizadas e incorporadas ao estudo, em especial no que se refere às alternativas de desenvolvimento indicadas pelos participantes.

\subsection{Caracterização do arranjo produtivo e} inovativo local de fitoterápicos do Amapá: resultados

\subsubsection{Centro indutor de inovação}

O Centro Indutor de Inovação do Arranjo Produtivo Local de Fitoterápicos do Estado do Amapá é composto principalmente pelas entidades que congregam pesquisadores que desenvolvem estudos e tecnologias relacionadas com o setor, em especial o Instituto de Pesquisa Cientifica e Tecnológica do Amapá - IEPA; a Universidade Federal do Amapá - UNIFAP e a Empresa Brasileira de Pesquisa Agropecuária - EMBRAPA.

O Instituto de Pesquisa Cientifica e Tecnológica do Amapá - IEPA tem se apresentado como um significativo agente indutor de inovação, por meio das ações de produção de conhecimento, desenvolvimento tecnológico e atendimento/comercialização mediante atuação da Divisão de Fitoterapia (que desenvolve trabalhos de acompanhamento ambulatorial de grupos tratados com fitoterápicos), da Farmácia de Produção e Comercialização de Fitoterápicos e Fitocosméticos e da Curadoria de Farmácias Vivas (onde são produzidas mudas de plantas medicinais e parte da matéria-prima utilizada na produção de medicamentos manipulados).

Os esforços das Políticas Públicas de incentivo à fitoterapia desenvolvidas pelo IEPA entre 19952002, se, por um lado, caminhavam ao encontro de condicionantes culturais existentes na formação da sociedade amapaense quanto ao uso de produtos naturais no tratamento de doenças, por outro lado, enfrentavam a oposição ferrenha de inimigos na esfera política governamental e de alguns profissionais da área médica.

Essas oposições tinham motivos diversos e por várias vezes houve tentativas de fechar a farmácia e inviabilizar as atividades de pesquisa com fitoterápicos do IEPA. Entre 2003 a 2010, com a mudança de governo, houve uma política de enfraquecimento do IEPA, motivada pela visibilidade alcançada, como uma das principais marcas da gestão pública anterior.

O quadro se agrava a partir de 2006 com a criação da Universidade Estadual do Amapá, que irá disputar com o IEPA, de forma política, os poucos recursos disponibilizados para C\&T no Amapá.

Com isso, as atividades com fitoterápicos e plantas medicinais, que alcançaram um razoável reconhecimento pelos amapaenses, foram desarticuladas, chegando ao fechamento da farmácia de manipulação de fitoterápicos devido à falta de manutenção da sua infraestrutura. O mesmo aconteceu com as farmácias da terra, que recebiam a assistência tecnológica do Instituto, ficando também com dificuldades de se manterem financeiramente.

Atualmente, a produção de fitoterápicos do IEPA é realizada com matéria-prima cultivada de 
forma agroecológica, produzida pelo campo de produção que o Instituto mantém no Município de Porto Grande, conforme preconiza a legislação de fitoterápicos, atendendo metade das necessidades da farmácia. A outra metade provém do extrativismo, coletada na floresta por fornecedores que são orientados tecnicamente pelos pesquisadores ou ainda coletadas por mateiros $^{2}$ da instituição, obedecendo à orientação da legislação quanto aos critérios de sustentabilidade ambiental.

O relatório anual da Divisão de Fitoterapia (ano) mostra um atendimento médio diário de 80 pessoas, e os produtos mais demandados por esses consumidores em 2012 foram: Xarope de Urucum e Jucá; Xarope de Eucalipto, Carucaá e Jutaí; Tintura de casca doce e sucuúba; Tintura de Jacareúba; Pomada de muirapuama e mururé-pajé; Pomada de eucalipto e cabacinha; Colutório de copaíba, gengibre e jucá e Tintura de alho, gengibre e gergelim.

O IEPA, no seu planejamento estratégico de médio prazo, segundo seu Diretor-Presidente, resolveu ousar nas suas estratégias de promoção da fitoterapia no Amapá com a colocação de medicamentos fitoterápicos na rede estadual e nacional de Saúde Pública (SUS), com a pretensão de iniciar com um medicamento no primeiro semestre de 2013 (que será um fitoterápico para uso tópico) até chegar a três fitoterápicos incluídos na Farmacopeia brasileira no final de 2014. Para isso, conta com o aporte de recursos oriundos de projeto aprovado pelo governo do Amapá no Fundo Amazônia do Banco Nacional de Desenvolvimento Econômico e Social (BNDES), para construção de uma Planta Industrial para produção de fitoterápicos. Nesse projeto, pretende-se trabalhar com produtores de matéria-prima, que serão orientados pelo Instituto para atender às normas da legislação, por meio da utilização de práticas agroecológicas, com as mudas fornecidas pelo IEPA. Os principais riscos para o empreendimento, na visão do dirigente, são: as pressões das grandes indústrias farmacêuticas para inibir a produção de fitoterápicos; o rigor da legislação; a operacionalização ineficiente em função de possíveis vícios de gestão na cultura do serviço público; a insuficiência de pessoal qualificado e, principalmente, a manutenção da vontade política do governo.

Quanto às estratégias incorporadas pelo IEPA para o apoio da produção de fitoterápicos no Amapá, vale destacar os esforços de abertura de edital para incubação de empresas para produção, a previsão de investimentos em cursos de formação de fitoterapeutas (por meio de uma especialização envolvendo as universidades estadual e federal, destinada aos profissionais de saúde) e iniciativas junto ao curso de Medicina da UNIFAP, para divulgar aos futuros médicos as vantagens das atividades fitoterapêuticas. $\mathrm{O}$ instituto também tem implementado ações voltadas para a elaboração das monografias de 11 plantas fitoterápicas, com base na Farmacopeia brasileira, e dos formulários e orientações para a prescrição.

Para o gestor do IEPA, os principais fatores que inibem o desenvolvimento da fitoterapia como negócio no Amapá são: a falta de empreendedorismo local; a legislação rigorosa e a pouca competência tecnológica e empresarial. Quanto à rejeição que havia no passado dos profissionais médicos para prescrever fitoterápicos, o atual gestor afirma que já existe uma procura por medicamentos do IEPA, incluídos em receitas médicas e, em alguns casos, apenas a indicação médica, principalmente para doenças crônicas.

\footnotetext{
2 Trabalhadores sem instrução formal, mas com profundo conhecimento da floresta e de seus recursos florestais, utilizados como guia e na coleta de produtos da floresta.
} 
Quanto ao trabalho do IEPA com as farmácias vivas, existem dificuldades de retomada pela falta de pessoal para atender à demanda existente. Durante a coleta de dados, o instituto denotava retornar parte do trabalho que desempenhava antes com as parteiras tradicionais, no registro do ofício de parteira, mantendo também o antigo grupo de Avaliação Clínica para as atividades etnográficas de resgate e valorização do conhecimento tradicional na utilização dos recursos naturais locais para tratamento de doenças.

A outra instituição que vem se fortalecendo no viés da indução de inovação na fitoterapia é a Universidade Federal do Amapá-UNIFAP, que, ao criar os cursos de Medicina e Ciências Farmacêuticas a partir de 2008, aumentou significativamente a capacidade de pesquisa e formação de profissionais para atuar nas atividades fitoterapêuticas. Nessa área, foi aprovado um curso de mestrado em Ciências Farmacêuticas e um doutorado em parceria com outras universidades brasileiras, tendo o apoio de professores de universidades da França com atuação na Guiana Francesa.

Em 2013, a UNIFAP mantinha ativos três grupos de pesquisa que desenvolviam trabalhos com plantas amazônicas (Grupo de Pesquisa em Química de Produtos Naturais; Grupo de Pesquisa em Fármacos e Grupo de Pesquisa em Bioativos
Amazônicos), por meio de 25 projetos de pesquisas com plantas de uso medicinal. Somados aos grupos de pesquisa, a UNIFAP dinamiza dois Programas de Pós-Graduação com uma forte interface com a fitoterapia, que é o Programa de Pós-graduação em Biodiversidade Tropical - com curso de mestrado e doutorado, com linha de pesquisa no uso sustentável da biodiversidade -, e o Programa de Pós-Graduação em Ciências da Saúde, no qual são desenvolvidos estudos com uso de plantas medicinais.

Por mais que a Empresa Brasileira de Pesquisa Agropecuária - EMBRAPA não tenha concentrado seus esforços de pesquisa e desenvolvimento na área de fitoterápicos no Estado do Amapá, foi identificado que a entidade possui um pesquisador que desenvolve pesquisas individuais com algumas espécies medicinais.

\subsubsection{Estruturas intermediárias da inovação}

Entende-se como Estruturas Intermediárias de Inovação o conjunto de Farmácias de Manipulação, Farmácias da Terra e Escolas-Famílias que desenvolvem atividades de produção, distribuição e comercialização de fitoterápicos nos diversos municípios do Estado do Amapá, conforme descrição contida na Tabela 5.

TABELA 5 - Descrição dos tipos de estruturas intermediárias de inovação.

\begin{tabular}{ll}
\hline $\begin{array}{l}\text { FARMÁCIAS DE } \\
\text { MANIPULAÇÃO }\end{array}$ & $\begin{array}{l}\text { Estabelecimento de manipulação de fórmulas magistrais e oficinais, para uso humano, que também dispensa e presta } \\
\text { assistência farmacêutica (RDC } \mathrm{n}^{\circ} \text { 67, de } 8 \text { de outubro de 2007). }\end{array}$ \\
\hline ESCOLA- FAMÍLIA & $\begin{array}{l}\text { São escolas de ensino fundamental e/ou médio que adotam a metodologia da alternância, que se trata do processo } \\
\text { de ensino-aprendizagem que acontece em espaços e territórios diferenciados e alternados. O primeiro é o espaço } \\
\text { familiar e a comunidade de origem (realidade); em segundo, a escola onde o educando/a partilha os diversos saberes } \\
\text { que possui com os outros atores/as e se reflete sobre eles em bases científicas (reflexão); e, por fim, retorna-se à } \\
\text { família e à comunidade, a fim de continuar a práxis (prática + teoria), seja na comunidade, na propriedade (atividades } \\
\text { de técnicas agrícolas) ou na inserção em determinados movimentos sociais. (MDA, 1999). }\end{array}$ \\
\hline \multirow{2}{*}{$\begin{array}{l}\text { FARMÁCIA DA } \\
\text { TERRA }\end{array}$} & $\begin{array}{l}\text { Uso de plantas medicinais no atendimento de saúde básica das comunidades rurais é um projeto premiado em 2003 } \\
\text { como Tecnologia Social pela Fundação Banco do Brasil, cujo objetivo é melhorar a saúde pública valorizando o } \\
\text { uso das plantas medicinais, estimulando as pessoas a resgatar conhecimentos milenares que podem estar nos seus } \\
\text { próprios quintais, plantados em hortas ou em vasos como meros objetos de decoração. }\end{array}$ \\
\hline
\end{tabular}


$\mathrm{Na}$ fase de mapeamento, foram identificados 20 agentes intermediários de inovação e, entre eles, 17 (85\%) foram selecionados para análise. As organizações que compõem as estruturas intermediárias de inovação possuem um período variado de atuação na região, sendo as Escolas-Famílias aquelas que possuem maior tempo de existência no mercado (14 anos), seguidas pelas Farmácias de Manipulação e Farmácias da Terra, com duração média de 12,3 anos e 13,5 anos, respectivamente. No que se refere à infraestrutura, um montante significativo das organizações possui salas para aulas, reuniões e/ou treinamento $(88,2 \%)$ e áreas de vendas (64,7\%). Entretanto, apenas as Farmácias de Manipulação apresentaram áreas consolidadas de rotulagem e embalagem, de processamento, laboratórios de produção de fitoterápicos e salas de assistência farmacêutica.

Vale destacar também que as Farmácias de Manipulação e Farmácias da Terra envolvem uma quantidade maior de pessoas em suas operações (Média de 16 e de 15,75 pessoas, respectivamente), seguidas pelas Escolas-Famílias (Média de 11,5 pessoas). Ainda sob a perspectiva do número de pessoal ocupado, percebe-se um aumento gradual da quantidade de pessoas absorvidas pelas organizações do setor, com forte indução promovida, em especial, pelo crescimento das Farmácias de Manipulação. Das organizações analisadas, 64,7\% não apresentaram faturamento anual. Isso se aplica a algumas Escola-Famílias e a algumas Farmácias da Terra, visto que se caracterizam como entidades fomentadas por ações governamentais e estão ancoradas no propósito de promover educação social por meio do compartilhamento e aplicação de saberes vinculados ao uso de plantas medicinais. $\mathrm{O}$ faturamento anual das outras organizações não apresentou convergência para nenhuma faixa estabelecida no estudo, entretanto, as Farmácias de Manipulação foram as que apresentaram maior faturamento (entre R\$ 840.000 e R\$ 1.200.000 anuais), e as Escolas famílias foram as que se apresentaram com menor faturamento anual (até R\$ 60.000,00).

A maior parte das matérias-primas e equipamentos é adquirida fora do estado, exceto alguns insumos agrícolas, açúcar, terras para canteiros, álcool, materiais de informática e luvas. As principais matérias-primas vegetais obtidas localmente são as cascas, frutas, raízes e óleos. Os serviços especializados que são demandados com frequência são: coleta de lixo, manutenção de computadores e ar condicionado e de orientação farmacêutica. Vale destacar que, enquanto a escolha dos insumos farmacêuticos é determinada pelo fato de serem necessários para realização de oficinas de treinamento, a aquisição das matérias-primas locais de natureza vegetal é determinada, em especial, pelo preço, pela política de doação de insumos pelo IEPA e pela proximidade com os fornecedores.

Sob a perspectiva da venda local de produtos, as Farmácias da Terra e Farmácias-Famílias se concentram na oferta de matérias-primas cultiváveis, plantas ornamentais e medicinais. Já as Farmácias de Manipulação possuem seus focos no oferecimento de complementos alimentares, produtos fitoterápicos e produtos fitocosméticos regulamentados pela ANVISA. Os principais produtos comercializados pelas Farmácias da Terra e Escolas-Família são as cascas, raízes, resinas, óleos e xaropes. Já as Farmácias de Manipulação ofertam seus produtos nas formas de encapsulados, balas, chás, farinhas, xaropes, óvulos, sabonetes de tratamento, shampoos, cremes, loções, géis e pomadas. Conforme informações obtidas por meio das estruturas intermediárias de inovação, as principais enfermidades tratadas com os seus produtos são: problemas hepáticos, diarreias, asma, gastrites, gripe, ameba, anemia, bronquite e doenças de pele. 
As principais dificuldades indicadas pelos sujeitos da pesquisa e relacionadas à operação das organizações foram: a) mecanismo insuficientemente capaz de possibilitar o financiamento das atividades administrativas e educacionais das Escolas-Famílias e Escolas da Terra e b) fragilidade do sistema de logística e transporte.

A pesquisa mostrou que produtores enquadrados na estrutura intermediária de inovação apresentam uma produção mais elaborada, sob o ponto de vista técnico, para coletar, manipular e comercializar as plantas medicinais e os produtos fitoterápicos nas formas de tinturas, pílulas e unguento (no caso das farmácias de manipulação) e na forma de plantas medicinais in natura nas farmácias da terra. Nesse sentido, as respostas obtidas quanto às questões de inovação, cooperação e aprendizado foram convergentes para as farmácias de manipulação, pois a legislação de fitoterápicos inibe uma produção mais diversificada. Entretanto, nas farmácias vivas, como a vigilância e as próprias regras são menores, a variedade de produtos é um pouco maior, embora prevaleçam as espécies de uso mais tradicionais.

Os tipos de inovações que estes produtores afirmam ter desenvolvido nos últimos anos dizem respeito ao lançamento de novos produtos já existentes no mercado. Os produtos citados pelas farmácias de manipulação foram principalmente cápsulas fitoterápicas de uva, alcachofra, coco, cártamo, folha negra, alcachofra, berinjela e cosméticos de plantas medicinais. Nas farmácias vivas, as inovações principais citadas foram a ampliação de canteiros com novas plantas e canteiros para produção de fitoterápicos. Os impactos resultantes das inovações introduzidas durante os últimos três anos foram: melhoria na efetividade dos produtos consumidos; ampliação da gama de produtos/serviços ofertados e melhoria na qualidade dos serviços e produtos.
Outros impactos também foram percebidos, como o pequeno o aumento (em alguns casos) da parcela do mercado de fitoterápico e o enquadramento de algumas organizações nas regulamentações e normas padrão.

Quanto aos atores envolvidos na articulação e colaboração com a introdução de inovações, os entrevistados apontam alunos, técnicos e mantenedores das Escolas- Famílias, técnicos do governo, pesquisadores do IEPA, técnicos do SESC, instrutores, educadores e membros da comunidade. Quanto aos processos de cooperação, os dados mostram que os $68,8 \%$ dos produtores de fitoterápicos no Amapá estabeleceram parcerias com o IEPA, cujos objetivos principais foram relacionados à capacitação e orientações técnicas. As parcerias com órgãos de governo também foram identificadas por $37,5 \%$ dos entrevistados, representados principalmente pelas Escolas-Famílias que, para funcionarem, precisam estabelecer convênios com as Secretarias de Educação, por exemplo. Também, 37,7\% construíram relações com outros tipos de organizações, como agências financeiras, estabelecimentos de ensino e franquias. Alguns atores estabeleceram cooperações com entidades associativas, beneficentes, organizações não governamentais, bem como com outros centros de capacitação para atividades de qualificação técnica e gerencial.

\subsubsection{Estruturas básicas da inovação}

Entende-se como Estruturas Básicas da Inovação o conjunto de coletores, garrafeiros, benzedeiras, erveiras e parteiras que desenvolvem atividades de coleta, cultivo, manipulação e aplicação de fitoterápicos nos diversos municípios do Estado do Amapá, conforme descrição contida na Tabela 6 . 
TABELA 6 - Descrição dos tipos de estruturas básicas de inovação.

\begin{tabular}{ll}
\hline $\begin{array}{l}\text { COLETORES OU } \\
\text { COLETADORES }\end{array}$ & $\begin{array}{l}\text { Pessoas responsáveis em coletar as plantas medicinais para produção de fitoterápicos, podendo ser ou não um produtor } \\
\text { rural ou extrativista. }\end{array}$ \\
\hline CULTIVADORES & Produtor agrícola de plantas medicinais. \\
\hline GARRAFEIROS & $\begin{array}{l}\text { Pessoa que tradicionalmente detém conhecimento sobre plantas medicinais e as usa para preparar remédios para vários } \\
\text { tipos de doenças, utilizando técnicas de manipulação não convencionais e armazenando os remédios produzidos em } \\
\text { garrafas, que são vendidas nas feiras livres das cidades. }\end{array}$ \\
\hline BENZEDEIRAS & $\begin{array}{l}\text { Também chamadas de rezadeiras, são pessoas que tradicionalmente rezam e abençoam os males que afligem o povo, } \\
\text { sobretudo os pobres. Não existe benzedeira sem que haja uma comunidade que busque suas orações. Mesmo assim, } \\
\text { recorrem a ela pessoas de todas as classes sociais. }\end{array}$ \\
\hline ERVEIRAS & $\begin{array}{l}\text { Comerciante de ervas, banhos e essências. } \\
\text { PARTEIRAS }\end{array}$ \\
$\begin{array}{l}\text { Em muitos lugares, a parteira é conhecida como parteira leiga, aparadeira, comadre, mãe de umbigo, curiosa, entre } \\
\text { outras denominaçes. Porém, o Ministério da Saúde adota a denominação de parteira tradicional, por considerar que } \\
\text { esse termo valoriza os saberes e práticas tradicionais e caracteriza a sua formação e o conhecimento que ela detém. As } \\
\text { parteiras indígenas e quilombolas estão incluídas entre as parteiras tradicionais, respeitando-se as suas especificidades } \\
\text { étnicas e culturais. }\end{array}$ \\
\hline
\end{tabular}

FONTE: Próprios Autores.

Vários agentes (em especial os coletores, benzedeiras e erveiras) adquirem os insumos de seus próprios canteiros de plantação para realizarem a manufatura de seus produtos e prestação de seus serviços. Outra parcela significativa adquire seus insumos de fornecedores, dependendo da especificidade de cada produto e de seu posicionamento entre os elos da cadeia produtiva, principalmente nos Municípios de Macapá, Mazagão e Laranjal do Jari. Entre os principais insumos utilizados na produção, vale destacar os óleos aromáticos e medicinais, sementes, cascas, mudas, plantas/ervas, raízes, leites, resinas, garrafadas de produtos extrativistas, maços de plantas medicinais, entre outros.

Os produtos/serviços mais ofertados aos consumidores finais são os óleos vegetais, as garrafadas, as ervas aromáticas e/ou medicinais (disponibilizadas em forma de mudas e/ou maços), as cascas, as bençãos (com o propósito de curar doenças, espantar mal olhado, proteger o corpo, purificar e tirar encanto do corpo e tirar quebranto de criança), as raízes e as folhas. Nesse contexto, vários produtos naturais da região são utilizados, como Carapa guianensis (andiroba), Dalbergia subcymosa (verônica), Pentachletra macroloba (pracaxi), Ouratea hexasperma (barbatimão), Aloe barbadensis (babosa), Ruta graveolens (arruda), Justicia pectoralis (amador), Tanacetum vulgare (catinga de mulata), Mentha pulegiun (hortelanzinho), Ocimun minimun (manjericão), Pagosteman heyheanus (oriza), Vernonia condensata (boldo), Bertholletia excelsa (castanha do brasil), Copaifera sp. (copaíba), Brosimum potabile (amapazeiro), Syagrus coronata (ourucurí), entre outros.

Os consumidores, ao buscarem os produtos ofertados pelos agentes vinculados à Estrutura Básica de Inovação, visam enfrentar um espectro variado de enfermidades como: artrite/artrose, reumatismo, sinusite, anemia, doenças de pele, queimaduras, gastrites, doença de mulher, feridas diversas, problemas hepáticos, ameba, asma, gripe, problemas renais, tosse, pressão alta, úlceras, entre outras.

As principais dificuldades operativas encontradas pelos agentes vinculados à Estrutura Básica de Inovação se concentram na precariedade da estrutura física dos pontos de venda (em especial nas feiras), na precariedade do sistema de transporte da produção e dos próprios agentes, na falta de 
incentivo governamental para a produção artesanal dos produtos vegetais, na regulamentação junto às prefeituras e vigilância sanitária, no preço das matérias-primas e na informalidade do setor. Frente a esse contexto, os agentes apontam como determinantes para uma boa operação das atividades a destinação de locais específicos e estruturados para os vendedores; a melhoria no sistema de transporte público e nas vias de escoamento produtivo; a organização da cadeia produtiva; o incentivo financeiro para produção, bem como a legalização, regulamentação e fiscalização dos serviços e atividades de venda de produtos fitoterápicos junto às prefeituras. As vantagens de localização dos produtores consideradas mais importantes foram a infraestrutura física, a proximidade de clientes e consumidores e a proximidade de fornecedores de insumos e matéria-prima.

A pesquisa mostrou que produtores enquadrados na Estrutura Básica de Inovação apresentam uma produção de natureza artesanal, utilizando dos seus conhecimentos tradicionais para coletar, manipular e comercializar as plantas medicinais e os produtos fitoterápicos nas formas principais de óleos vegetais, garrafadas e ervas aromáticas e/ou medicinais. Esse conhecimento foi herdado dos antepassados e geralmente se encontra associado a outras formas míticas como crendices e bênçãos.

Nesse sentido, as respostas quanto às questões de inovação, cooperação e aprendizado se apresentaram muito estéreis, pelo próprio tipo de conhecimento (do tipo popular) que vem da tradição e é repassado em processos informais de tal forma que as inovações acabam tendo um caráter pouco perceptível. As únicas inovações reconhecidas nessa amostra foram a melhoria da coleta de Syagrus coronata (ouricuri) (que é uma palmeira da região, que tem efeito repelente contra os mosquitos), descrita por um coletor que fornece matéria-prima para ser industrializada como vela por uma empresa incubada no IEPA; e mudanças nos conceitos e/ou prática de marketing e comercialização descritas por uma benzedeira/erveira.

\subsubsection{Estruturas de consumo}

Entende-se como Estruturas de Consumo da Inovação o conjunto de consumidores que frequentam e fazem uso dos fitoterápicos nos diversos municípios do Amapá. Para o presente estudo, foram selecionados 200 consumidores que frequentam as Farmácias de Manipulação e Feiras de Produtores de Macapá, concentrando $59,48 \%$ da população daquela Unidade Federativa.

Os consumidores entrevistados são, em sua maioria, mulheres $(64,54 \%)$ na faixa etária de 45 a 54 anos $(34,34 \%)$, o que, de certa forma, sinaliza um provável perfil predominante de frequentadores do mercado de plantas medicinais e fitoterápicos de mulheres de meia idade. O comprador de fitoterápicos e plantas medicinais encontra-se majoritariamente residindo na região a mais de 40 anos $(43,65 \%)$. Os dados podem indicar que o uso de fitoterápicos e plantas medicinais no Amapá é uma prática predominante dos moradores nativos e/ou dos que moram há muitos anos no Amapá. A pesquisa mostra também que a maioria dos consumidores entrevistados é dos bairros mais antigos, onde moram as populações mais tradicionais de Macapá e que ficam próximos dos locais de venda dos medicamentos e fitoterápicos. Nos bairros mais novos, moram os que migraram recentemente; são bairros mais distantes dos locais de venda de fitoterápicos e plantas medicinais.

Quanto ao conhecimento e uso de plantas medicinais, os dados da pesquisa indicam que $87,37 \%$ dos entrevistados dizem conhecer plantas medici- 
nais, enquanto $12,63 \%$ negam esse conhecimento. Observa-se que o cultivo de plantas medicinais está presente nas residências de $68,69 \%$ dos entrevistados, que afirmam ter alguma planta cultivada em casa, enquanto $31,31 \%$ afirmam não ter essa prática.

Quando abordados sobre se já utilizaram alguma vez plantas para tratar doenças, $95,43 \%$ dos pesquisados relatam positivamente, enquanto $4,57 \%$ afirmam que nunca utilizaram esse produto. As principais doenças contra as quais se utilizam as plantas foram: gastrites, problemas renais, doença de mulher e diarreias. Em menor número, foram relatadas enfermidades que englobam problemas hepáticos, gripes, diabetes, tosses, doenças de pele e ameba.

Quanto à forma de utilização das plantas medicinais para tratar as doenças, os dados mostram que os usuários utilizam com mais frequência as formas de chá $(49,1 \%)$, seguidas de garrafadas (23,8\%), sumo $(7,3 \%)$, banhos aromáticos $(4,9 \%)$ e inalação $(1,6 \%)$.

No que se refere ao local de aquisição de plantas medicinais, $72,7 \%$ dos sujeitos pesquisados afirmaram obter em mais de um local, em especial nas feiras de agricultor (42,7\%), seguidas pelas casas de ervas $(28,1 \%)$, e apenas $5,6 \%$ referiram-se às compras diretas do produtor ou extrativista.

\subsubsection{Representação esquemática do arranjo produtivo e inovativo local de fitoterápicos do Amapá}

O Arranjo Produtivo Local de fitoterápicos do Estado do Amapá se configura por uma série de relações envolvendo um conjunto de agentes que possuem potencial de interação direta ou indireta nas principais atividades produtivas do setor, conforme esquematizado a seguir (Figura 5).
Sob a perspectiva do contexto macroeconômico, o Arranjo Produtivo é influenciado pelos elementos geopolítico, de financiamento e de política de comércio internacionais; pelas políticas e infraestruturas nacionais de Ciência, Tecnologia e Inovação; pela própria infraestrutura produtiva nacional vinculada ao setor e pelos marcos regulatórios relacionados com a fitoterapia no Brasil.

Circunscrito ao Arranjo Produtivo, tanto o Governo do Estado do Amapá (por meio da atuação do Conselho Gestor de Arranjos Produtivos Locais e de ações de apoio político-institucional), quanto as prefeituras municipais assumem o papel de entidades potenciais de apoio direto e indireto ao setor, sendo o Banco Nacional do Desenvolvimento BNDES, o Conselho Nacional de Desenvolvimento Científico e Tecnológico - CNPq e o Ministério da Saúde (por meio do Programa de Pesquisa para o SUS) as principais organizações de financiamento capazes de fomentar o desenvolvimento setorial.

O Arranjo de Fitoterápicos do Amapá congrega, na capital do Estado, instituições que promovem o desenvolvimento educativo, investigativo e formativo, em especial o Instituto de Pesquisa Cientifica e Tecnológica do Amapá - IEPA; a Universidade Federal do Amapá - UNIFAP; a Empresa Brasileira de Pesquisa Agropecuária - EMBRAPA e o Instituto de Desenvolvimento Rural do Amapá - RURAP. Sob a perspectiva das entidades da sociedade civil organizada, estão presentes no setor a Rede das Associações das Escolas-Famílias do Amapá - RAEFAP; o Sindicato dos Trabalhadores Rurais do Amapá - STR/AP; Associação das Mulheres Produtoras da Foz do Rio Mazagão Velho - AMPAFOZ e Conselhos Regionais de Medicina, Enfermagem e de Farmácia do Amapá-CREMAP/ COREM/CRF.

A cadeia produtiva de fitoterápicos se caracteriza pela conjugação de diversos fornecedores 


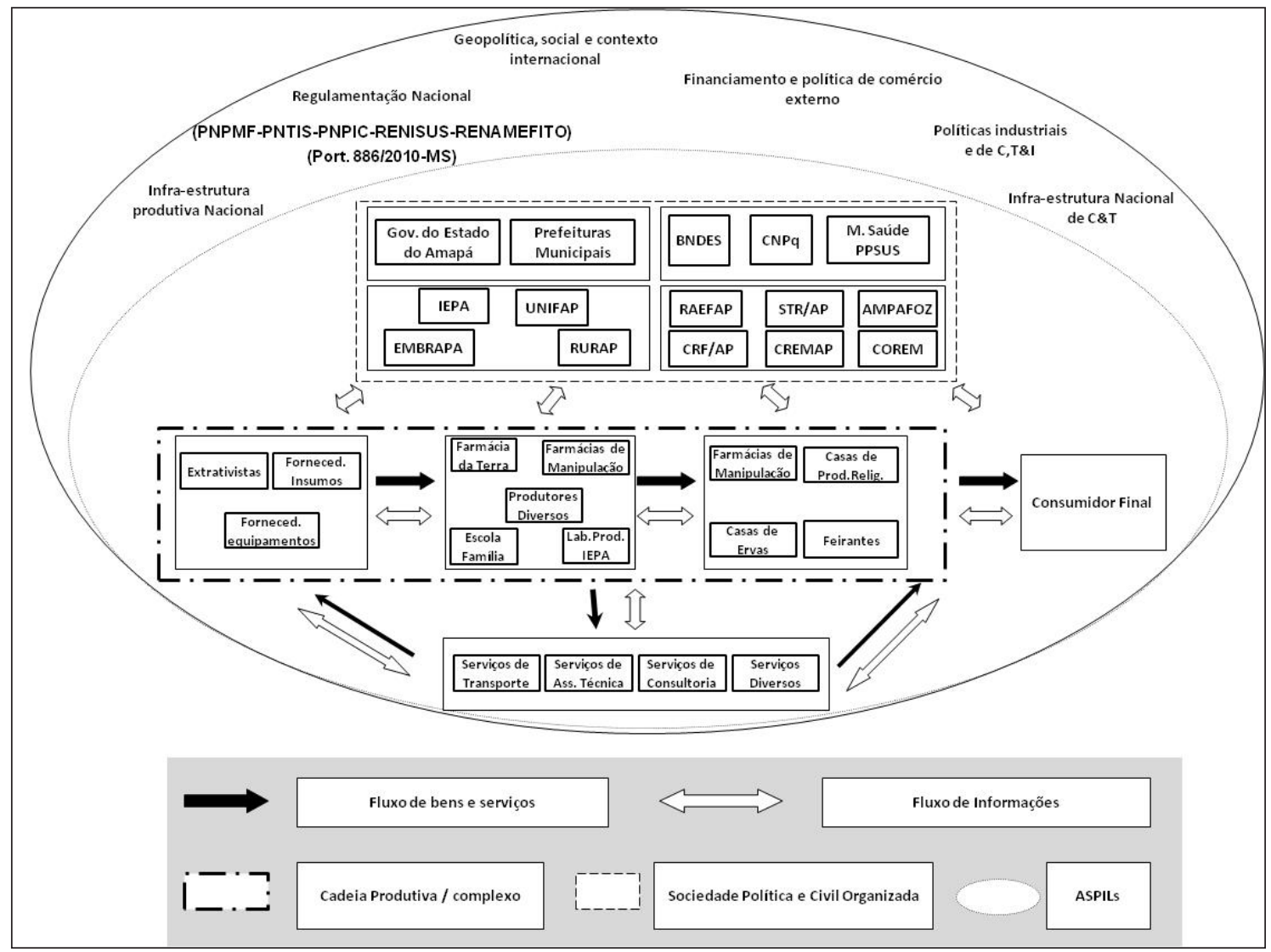

FIGURA 5 - Representação esquemática do arranjo produtivo local de fitoterápicos do estado do Amapá. FONTE: Próprios Autores.

(extrativistas e fornecedores de insumos e equipamentos), de agentes produtores (Farmácias da Terra, Farmácias de Manipulação, Escolas-Famílias, Laboratório do IEPA e produtores diversos) e agentes comerciantes que oferecem seus produtos aos clientes finais como as Farmácias de Manipulação, as Casas de Ervas e produtos religiosos e feirantes. Vale destacar que os diversos agentes da cadeia produtiva usam os mais variados serviços de apoio, como de transporte, de assistência técnica de consultoria, entre outros.

$\mathrm{O}$ estudo identificou fragilidades e potencialidades existentes para o avanço da fitoterapia no
Estado do Amapá. A principal fragilidade diz respeito ao papel indutor do governo, em que os avanços ficam a mercê da vontade política dos governantes. No caso específico do Amapá, foram relatadas interrupções de políticas de desenvolvimento da fitoterapia pelo IEPA nas mudanças de governo. A parceria e o maior envolvimento do setor não governamental nas políticas que envolvem essas atividades são ingredientes fundamentais para a consolidação dos avanços possíveis.

Quanto às potencialidades de utilização da fitoterapia como um negócio atrativo para o setor privado, as limitações da legislação têm sido um 
fator inibitório desses avanços. Na visão de um dos especialistas entrevistados, um dos fatores que tem inibido a utilização de produtos nacionais na indústria de fitoterápico é a falta de estudos de validação dos produtos e de toda a cadeia produtiva vinculada a eles.

Atualmente, existe uma tentativa de construir um grande banco de dados nacional dos estudos já desenvolvidos para as plantas brasileiras, que certamente irá contribuir decisivamente na liberação de mais produtos com essas espécies. O IEPA vem procurando fazer banco de dados com 11 plantas locais, para a tentativa de liberação no futuro. Segundo especialistas entrevistados, os estudos existem, contudo, falta juntá-los e complementá-los para atender às exigências dos processos de liberação. Esse fator torna-se um elemento determinante para o fato de as Farmácias de Manipulação não utilizarem os produtos regionais como medicamentos, na medida em que não atendem à legislação vigente. Os produtos oriundos de plantas e oferecidos aos consumidores são comercializados como complementos alimentares (vários dos quais são utilizados como emagrecedores) e como cosméticos (cenário em que a empresa Natura tem conseguido grandes avanços com plantas amazônicas).

As Farmácias Vivas, no caso do tratamento com plantas medicinais, apresentam uma possibilidade concreta de contribuição para a inclusão social. As restrições legais são menores e são plantas utilizadas tradicionalmente pela população, contribuindo para reduzir os gastos com medicamentos. Nesse sentido, a utilização das Farmácias Vivas tem se proliferado em todo o país, sendo a ANVISA o órgão responsável pela regulamentação no que diz respeito às boas práticas no seu uso.

Quanto à capacidade inovativa e de inclusão social, no marco legal vigente, as suas potencialidades no Amapá são muito maiores. O IEPA possui uma experiência já consolidada nessa área, podendo, assim, contribuir para uma maior utilização da fitoterapia. A UNIFAP vem desenvolvendo pesquisa de validação da utilização dessas plantas; localmente, existe quantidade expressiva de consumidores que acreditam no seu poder terapêutico. A demanda existente pelas espécies das Farmácias Vivas é também influenciada pela precariedade da saúde pública nos municípios amapaenses.

No Amapá, as Escolas-Famílias, enquanto alternativa de educação no campo, têm contribuído na divulgação do uso das plantas medicinais das Farmácias Vivas, por utilizá-las na formação dos seus alunos, que são provenientes da zona rural, extremamente afetada pela precariedade dos serviços de saúde pública. Sob essa perspectiva, a Farmácia da Terra tem se apresentado como alternativa para a população, devido à constante falta de medicamentos básicos nos postos de saúde.

Quanto aos produtores informais, garrafeiros, parteiras, benzedeiras e fornecedores, seus conhecimentos são arraigados nas tradições. A capacidade de inovação é restrita e pode ser pensada na inclusão de boas práticas no processo de cultivo, de coleta, na produção das garrafadas e dos chás, semelhante ao que foi feito no passado pelo governo estadual no Programa Parteiras Tradicionais, em que houve um processo de qualificação básica sobre higiene e outros cuidados nas atividades de parto.

\section{Alternativas de desenvolvimento da fitoterapia no Amapá}

As perspectivas do desenvolvimento da fitoterapia no Amapá, enquanto um arranjo produtivo e inovativo, podem ser pensadas sob a ótica da fitoterapia como negócio e da fitoterapia como uma alternativa de inclusão social, envolvendo diversos atores, conforme elencado na Tabela 7 . 
TABELA 7 - Principais atores envolvidos potencialmente no desenvolvimento da fitoterapia no Amapá.

\begin{tabular}{clcl}
\hline \multicolumn{2}{c}{ A FITOTERAPIA COMO NEGÓCIO } & A FITOTERAPIA COMO UMA ALTERNATIVA DE INCLUSÃO \\
SOCIAL
\end{tabular}

FONTE: Próprios Autores.

\subsection{A fitoterapia como negócio}

Nessa perspectiva, onde existe uma grande dificuldade de investimentos empresariais devido às barreiras de atendimento das exigências da legislação em vigor, a estratégia do IEPA em investir na constituição de uma indústria de fitoterápicos é vista como a alternativa viável pelos especialistas do setor, pois oportuniza o aprimoramento do aprendizado local necessário para os novos avanços, inclusive com a possibilidade de implementação de parceria público privada.

O processo de aprendizado técnico e organizacional vinculado às ações do instituto se apresenta como potencial gerador de condições para superar a insegurança de empreendedores locais em relação aos riscos.

A estruturação dos cursos de graduação e pós-graduação em Ciências Farmacêuticas, ao contribuir para o desenvolvimento das pesquisas em fitofármacos, também é apontada como um fator contribuinte, de médio e longo prazos, para avanços, sendo a cooperação entre o IEPA e a UNIFAP considerada como desenho institucional promissor não só para o Amapá como para a Amazônia.

\subsection{A fitoterapia como uma alternativa de inclusão social}

A utilização das Farmácias Vivas é vista pelos especialistas como uma alternativa viável de inclusão social em função dos custos reduzidos, facilidades de produção e da cultura consumidora local que se amplia pela precariedade do sistema de saúde amapaense. Existe, ainda, presente na região, a prática do cultivo de planta medicinal nas residências, pela qual as famílias utilizam essas plantas com frequência no tratamento de doenças.

Enquanto o IEPA, as Escolas-Famílias, as Farmácias da Terra e os produtores informais (garrafeiros, parteiras, benzedeiras, etc.) divulgam e mantêm viva a utilização das plantas medicinais das Farmácias Vivas, a UNIFAP se apresenta como potencial núcleo desenvolvedor de pesquisas para validação. Dessa forma, existe uma série de fatores que se colocam como potenciais propulsores dessa prática na saúde pública amapaense.

Outra alternativa que se associa ao debate sobre essa temática é a possibilidade da participação dos sistemas municipais de saúde na utilização de fitoterápicos nas situações menos complexas e nas 
quais já existe uma segurança de uso. Porém, ainda se observa uma grande resistência institucional dos serviços municipais de saúde sobre essa questão. Raros municípios possuem algum tipo de experiência nessa direção nas suas unidades básicas de saúde. Conforme relatam alguns entrevistados, essa prática poderia ser levada adiante nos municípios pelo Serviço de Extensão Rural, por meio da capacitação dos extensionistas rurais ou ainda dos programas de saúde da família. Para tanto, seria necessário um processo de sensibilização, de divulgação e de capacitação dos profissionais que atuam nesses programas.

\section{Considerações finais}

Em síntese, a fitoterapia é uma atividade com grande potencial econômico no Amapá, dada a grande riqueza em biodiversidade, desenvolvida nos diferentes ecossistemas existentes, que possibilitaram, na formação cultural amapaense, uma grande variedade de utilização e de produtos, que permanece guardada no saber tradicional das populações locais. A utilização desse potencial como uma atividade capaz de gerar emprego, ocupação e renda mostra-se limitada, a curto e médio prazos, devido a uma série de fatores que se expressam nas dificuldades em atender à legislação existente.

A superação desses obstáculos passa por um investimento maior do poder público em mostrar para a iniciativa privada que isso é possível. O projeto de desenvolvimento da indústria de fitoterápico é uma proposta capaz de induzir um processo de melhor utilização econômica dessa potencialidade. $\mathrm{Na}$ visão dos especialistas, isso é possível, porém, exige um esforço local muito grande no resgate do conhecimento acadêmico já existente e na criação de condições de suprir as lacunas de conhecimentos por meio de novas pesquisas.

Mas, se as dificuldades para a produção industrial com apelo econômico são grandes, apenas uma ação muito bem organizada e com uma quantidade adequada de investimentos poderá tornar esse sonho institucional uma realidade sustentável, com a utilização das plantas medicinais. As Farmácias Vivas, que foram estimuladas pelo IEPA, mostram-se como uma possibilidade concreta de contribuir tanto para a inclusão social de setores que não conseguem comprar os medicamentos modernos como para melhoria dos indicadores de saúde pública no Amapá. Para isso, será necessária uma maior ação mobilizadora das organizações sociais que lutam no combate à pobreza, para forçar os investimentos na implantação das Farmácias da Terra nas políticas municipais de saúde pública.

Dentro desse contexto, se apresenta como relevante a discussão sobre diversos pontos considerados críticos no processo de desenvolvimento do setor. Entre eles, vale destacar: a) preocupação com a proteção do saber local; b) impactos provenientes da aprovação e implementação da nova legislação sobre procedimentos de controle de qualidade para as Farmácias Vivas; c) possíveis impactos relacionados com as novas tendências para a legislação da produção de fitoterápicos e d) estratégias de consolidação de uma governança local direcionada para a promoção do desenvolvimento do setor.

A pesquisa permitiu uma compreensão do dilema que enfrenta a política de fitoterapia no Amapá, considerado um estado que precisa fazer opções de investimentos importantes para o desenvolvimento local. Nesse ponto, abrem-se as alternativas de escolha de prioridades entre gerar oportunidades econômicas para uma população que cresce acima da média nacional e investir na melhoria da qualidade da saúde. 


\section{Agradecimentos}

Agradecemos ao esforço integrado das seguintes instituições envolvidas na pesquisa: Universidade Federal do Amapá - UNIFAP (Núcleo de Estratégia, Gestão e Estudos Organizacionais

\section{Referências}

Almeida, N. A trajetória institucional do IEPA: a origem do IEPA. In: Oliveira, A.; Nishi, N. (Orgs.). Ciência e tecnologia para o desenvolvimento sustentável. Macapá: 2001. p. 34-39.

Carreras, R. de la T.; Gonzalez, J. L. Las plantas aromáticas y medicinales: futuro y potencialidad en Extremadura. In: Martínez, J. M. C.; Pardo, E de M.; Blanco, R. G.; García, F. P. (Coord.). La agricultura y la ganadería extremeñas: informe 2010. Espanha, 2011. p. 139-152.

Daniel, Padre J. Tesouro descoberto no máximo rio Amazonas. Rio de Janeiro: Contraponto, 2004. 2 v.

Datasus. Banco de Dados do Sistema Único de Saúde. Disponível em: <http://www.datasus.gov.br $>$. Acesso em: 22 out. 2012.

Drummond, J. A.; Pereira, M. de A. P. O Amapá nos tempos do manganês: um estudo sobre o desenvolvimento de um estado amazônico. Rio de Janeiro: Garamond, 2007. p. 500.

Filocreão, A. S.; Galindo, A. G.; Santos, T. de J. S. dos; Carvalho, A. M. Arranjo produtivo local e inclusão social: o caso da fitoterapia no Estado do Amapá - Relatório Final. Rio de Janeiro: UFRJ/Instituto de Economia/Redesist/ Project RISSS, 2013. Disponível em: $<$ http://www.redesist. ie.ufrj.br/rissi/images/site/files/report/Final_report_-_Brazil.pdf $>$. Acesso em: 02 out. 2013.

FIRJAN. Federação das Indústrias do Estado do Rio de Janeiro. Disponível em: $<$ http://firjan.org.br $>$. Acesso em: 22 out. 2012.
- NEGEO/UNIFAP); Instituto de Pesquisas Científicas e Tecnológicas do Amapá - IEPA; Instituto de Economia da Universidade Federal do Rio de Janeiro - IE/ REDESIST/UFRJ; Fundação Universitária José Bonifácio - FUJB e International Development Research Centre - IDRC.

IBGE. Instituto Brasileiro de Geografia e Estatística. Censo IBGE. 2000. Disponível em: <http:// www.ibge.gov.br>. Acesso em: 22 out. 2013.

IBGE. Instituto Brasileiro de Geografia e Estatísticas. 2013. Disponível em: <http://www.ibge.gov.br $>$. Acesso em: 22 out. 2013

Matos, M. P. de; Soares, M. C. C.; Cassiolato, J. E. Conceptual and methodological framework of Local Innovative and Productive Systems: guidelines for case studies based on innovation and social inclusion. 2012. Disponível em: $<$ http://www.redesist.ie.ufrj.br/rissi/index.php/main-activities/research/case-studies $>$. Acesso em: 28 out. 2012.

Oliveira, A. Fitoterapia como alternativa de saúde pública. In: Oliveira, A.; Nishi, N. (Orgs.). Ciência e tecnologia para o desenvolvimento sustentável. Macapá, 2001. p.43-80.

Oliveira, A.; Nishi, N. (Orgs.). Ciência e tecnologia para o desenvolvimento sustentável. Macapá, 2001.

Perfeito, J. P. S. O registro sanitário de medicamentos fitoterápicos no Brasil: uma avaliação da situação atual e das razões de indeferimento. 162 p. Brasília, Dissertação (Programa de Pós-Graduação em Ciências da Saúde) - Universidade de Brasília, 2012.

Santos, T. de J. S. dos. Compilamento sobre as ações de fitoterapia no Amapá. Macapá: Mimeografado, 2003. 15p. 